685 INCIDENTAL INTRAVASCULAR LARGE B-CELL LYMPHOMA ARISING IN THE UTERINE MYOMETRIUM

${ }^{1,2} \mathrm{C}$ Yim* ${ }^{3} \mathrm{~K}$ Tang, ${ }^{1,2} \mathrm{KM}$ Wan. ${ }^{1}$ Royal Hospital for Women, Gynaecological Cancer Centre, Randwick, Australia; 'UNSW Sydney, School of Women's and Children's Health, Sydney, Australia; ${ }^{3}$ South Eastern Area Laboratory Services, Anatomical Pathology, Randwick, Australia

\subsection{6/ijgc-2021-ESG0.528}

Introduction/Background* IVLBCL is a rare subtype of B-cell lymphoma characterised by the proliferation of malignant lymphocytes within vascular lumina in the absence of an extravascular tumour mass. Due to its aggressive nature, systemic disease is often present at the time of diagnosis.

Methodology This is a case report of a a 55-year-old Chilean woman who was referred for management of a large complex ovarian mass suspicious for an ovarian neoplasm. She underwent a staging laparotomy, including a total abdominal hysterectomy, bilateral salpingo-oophorectomy, omentectomy and appendicectomy. A large, haemorrhagic, torted left ovarian mass weighing $6 \mathrm{~kg}$ was removed. The left ovarian cyst showed extensive haemorrhagic infarction related to previous torsion. However, on microscopic examination, the myometrium and endocervical mucosa showed numerous capillaries containing an intravascular population of large lymphoid cells with malignant cytologic atypia. Immunohistochemistry confirmed these cells were of B lymphocyte lineage, hence forming a diagnosis of intravascular large B-cell lymphoma (IVLBCL). Following referral to a haematological oncologist, a positron emission tomography (PET) scan found no other evidence of disease and our patient was recommended for surveillance.

Result(s)* 10 cases have been reported in the uterus, most of which present with abnormal vaginal bleeding or non-specific constitutional symptoms. There is no standardised treatment of IVLBCL, but most cases of uterine IVLBCL have been treated with both surgery and chemotherapy, with variable outcomes.

Conclusion* There is no standardised treatment of IVLBCL, but most cases of uterine IVLBCL have been treated with both surgery and chemotherapy, with variable outcomes.

\section{BREAST METASTASIS FROM OVARIAN CARCINOMA: ONE CASE REPORT AND REVIEW LITERATURE}

${ }^{1} \mathrm{~N}$ Doan*, ${ }^{*} \mathrm{~T}$ Nguyen, ${ }^{1} \mathrm{~L}$ Ta, ${ }^{1} \mathrm{Y}$ Nguyen, ${ }^{2} \mathrm{~T}$ Thai, ${ }^{3} \mathrm{~T}$ Quan, ${ }^{3} \mathrm{~A}$ Cung. ${ }^{1}$ Oncology Hospital at Ho Chi Minh city, Gynecology Surgery, Ho Chi Minh, Viet Nam; ${ }^{2}$ Oncology Hospital at Ho Chi Minh city, Pathology, Ho Chi Minh, Viet Nam; ${ }^{3}$ Oncology Hospital at Ho Chi Minh city, Radiology, Ho Chi Minh, Viet Nam

\subsection{6/ijgc-2021-ESG0.529}

Introduction/Background* Report one case of ovavian carcinoma metastasis breast mimicking the primary breast carcinoma

\section{Methodology}

Case report and review literature

Result(s)* Breast is an uncommon metastatic site of ovarian cancer with only $0.03-0.6 \%$ of all breast maglinancies. There are only 110 cases documented until 2015. The rarity of this circumstance can lead to insufficent diagnosis and overtreatment.

The case in our report was the 55-year old female. She had the breast tumor, ovarian tumor and supraclavicular lymph node. The H\&E images of all tumor showed adenoma carcinoma. We performed IHC stain eight markers, including WT1, PAX8, P16, p53, ER, PR, Mamma-globulin and Ki67. All tumor had the similar results with this panel markers. Detailly, WT1, PAX8, P16, p53, ER were positive and PR, Mamma-globulin were negative. According to these results, we concluded this was the case of ovarian carcinoma metastasis to breast and supraclavicular lymph node.

Conclusion* Surgical pathology and Immunohistochemistry play an important role in our case of determining the origin of the metastatic lesion of the breast therefore they give us precise diagnosis and staging. Sufficient assessment of this patient give us the reasonable mangement orientation without any overzealous treatment.

\section{EFFECT OF CIRCUMFERENTIAL TUMOR CAVITY SHAVING IN REDUCING THE RATE OF MASTECTOMY}

${ }^{1} \mathrm{~K}$ Ben Hamida*, ${ }^{1} \mathrm{~N}$ Tounsi, ${ }^{2} \mathrm{~S}$ Kamoun, ${ }^{1} \mathrm{H}$ Bouaziz, ${ }^{2} \mathrm{Y}$ Houcine, ${ }^{2} \mathrm{~K}$ Hamza, ${ }^{2} \mathrm{~K}$ Tili, ${ }^{2} \mathrm{~A}$ Goucha, ${ }^{2} \mathrm{~B}$ Bettaieb, ${ }^{1} \mathrm{~K}$ Rahal, ${ }^{2} \mathrm{M}$ Driss. ${ }^{1}$ Salah Azaiez Institute of Oncology, Department of Surgical Oncology, Tunis, Tunisia; ${ }^{2}$ Salah Azaiez Institute of Oncology, Department of Pathology, Tunisia

\subsection{6/ijgc-2021-ESG0.530}

Introduction/Background* Breast-Conserving Surgery (BCS) is considered a standard of care for women with early-stage breast cancer.

Achieving adequate margins of excision is a crucial component of breast surgery.

In our department, we routinely assess circumferential tumor cavity shaving (CTCS) status using frozen section analysis.

We sought to determine the effect of CTCS on reducing the rate of mastectomy with no residual disease.

Methodology We conducted a retrospective review of a prospectively maintained database of patients who underwent primary BCS for stage 0-III breast cancer between January 2015 and December 2019 in Salah Azaiez Institute of Oncology, Tunis, Tunisia.

We identified 142 patients who underwent conservative surgery with positive CTCS on histological examination.

Complementary treatment consisting in mastectomy was performed on all patients.

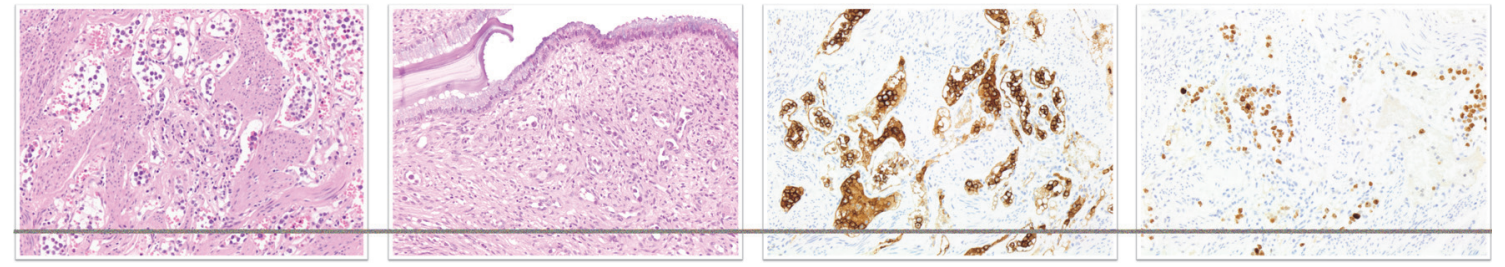


Result(s)* The mean age was 50. The average tumor size was $28 \mathrm{~mm}$. The tumor was bifocal in 20\%. 55\% of tumors were Grade II SBR.

Invasive ductal carcinoma (IDC) was the most common histological subtype (74\%). It was associated in $79 \%$ of cases with ductal carcinoma in situ (DCIS).

For the CTCS, $60 \%$ were DCIS, and $40 \%$ of the cases were invasive ductal carcinoma.

A complementary treatment consisting of mastectomy was indicated to all patients.

A residual tumor was detected in the remaining mammary gland in $60.4 \%$ of cases, out of which $39 \%$ were DCIS.

Chi-square test found that the presence of DCIS in CTCS, the lymphovascular invasion, and the size of tumors were not related to the presence of residual invasive or in-situ disease $(\mathrm{p}<0.05)$.

Conclusion* CTCS can help to detect residual or multifocal diseases.

Nevertheless, we need to find a way to avoid mastectomy with no residual disease in the remaining mammary gland.

\section{TUMOUR SIZE AND RESECTION MARGIN STATUS AFFECT RECURRENCES AND SURVIVAL IN RADIATION ASSOCIATED ANGIOSARCOMA OF THE BREAST}

${ }^{1} \mathrm{E}$ Fox ${ }^{*},{ }^{2} \mathrm{R}$ Merard, ${ }^{3} \mathrm{R}$ Warner, ${ }^{3} \mathrm{~S}$ Bains, ${ }^{4} \mathrm{~A}$ El-Ghobashy, ${ }^{1,5} \mathrm{~A}$ Shaaban. ${ }^{1} \mathrm{Ce}$ llular Pathology, Queen Elizabeth Hospital Birmingham, Birmingham, UK; ${ }^{2}$ Cellular Pathology, Queen Elizabeth Hospital Birmingham, UK; ${ }^{3}$ Oncoplastic Breast Surgery, Queen Elizabeth Hospital Birmingham, Birmingham, UK; ${ }^{4}$ Department of Gynaecological Oncology, The Royal Wolverhampton NHS Trust, Wolverhamptom, UK; ${ }^{5}$ University of Birmingham, Birmingham , UK

\subsection{6/ijgc-2021-ESG0.531}

Introduction/Background* Radiation associated angiosarcoma of the breast (RAAS) is a rare aggressive post-radiotherapy complication with an estimated incidence of $0.05-0.3 \%$. Currently, there is minimal evidence on presentation, outcome and factors affecting the likelihood of recurrence and survival. Methodology All patients diagnosed with RAAS, managed at the Birmingham Sarcoma Service (Birmingham, UK) between February 2013 and March 2021 were identified. Full clinical, pathological and patients' outcome data were collected. The non-parametric Mann-Whitney $U$ test was used to test statistical significance and receiver operating characteristic (ROC) curve was utilised to determine threshold values.

Result(s)* A total of 53 patients fulfilled inclusion criteria. Their previous breast cancer diagnosis spanned from 19822004. The median age at diagnosis was 71 years (range 5693). The median interval from radiotherapy to RAAS diagnosis was 8 years (range 1-37years). This interval has significantly shortened over the years $(\mathrm{p}<0.001)$. Sixteen patients $(30 \%)$ developed recurrent RAAS and 19 patients (36\%) died of the disease. The overall 5-year survival was $52.5 \%$.

Distance to resection margin was found to be highly significantly different $(p=0.002)$ between patients who had no recurrent RAAS (median clearance $16 \mathrm{~mm}$ ) and recurrent disease (median clearance $6 \mathrm{~mm}$ ). The threshold margin where recurrence was less likely to occur was $7.5 \mathrm{~mm}$ (area under the curve $(\mathrm{AUC})=0.769$, sensitivity $82.9 \%$, specificity $56.5 \%$ ).

Tumour size was significantly larger (median $102.5 \mathrm{~mm}$ ) in those patients who died compared to those who survived (median size $42.5 \mathrm{~mm} ; \mathrm{p}=0.02$ ). Patients with tumour sizes greater than $47.5 \mathrm{~mm}$ were more likely to die from the disease
(AUC $=0.701$, sensitivity 81.3\%, specificity 56.2\%). Neither patient age nor grade of the angiosarcoma correlated with lesional recurrence or patient outcome.

Conclusion* RAAS is associated with high likelihood of recurrences and mortality. Tumour size and margin status are significant predictors of recurrences and patient survival. Over the last decade, the number of diagnosed cases has increased with a shortening in the interval between radiotherapy and onset of RAAS. Due to the rarity and aggressiveness of the disease , management of RAAS at a specialist centre may provide superior outcomes.

\section{BRENNER BORDERLINE OVARIAN TUMOR: A CASE SERIES AND LITERATURE REVIEW}

G Ricotta*, A Maulard, P Pautier, A Leary, C Chargari, S Gouy, C Genestie, P Morice. Gustave Roussy, Villejuif, France

\subsection{6/ijgc-2021-ESG0.532}

Introduction/Background* Most frequent borderline ovarian tumors are serous and mucinous subtypes. Less frequent borderline diseases are endometrioid, clear cell and Brenner tumors (BBOT). Very few are known about this later subtype and most of reports concerns very short series or case reports. The aim of this study was to determine the prognosis of a continuous series of BBOT and to analyze data published in the literature about this rare entity.

Methodology A retrospective review of patients with BBOT treated or referred to our institutions. A centralized histological review by a reference pathologist and data on the clinical characteristics, management and outcomes of patients were required for inclusion.

Result(s)*

Seventeen patients were identified Median age was 62 (range 42-85) years. Six patients underwent a unilateral salpingooophorectomy and 11 a bilateral salpingo-oophorectomy +/hysterectomy and/or staging surgery. Sixteen patients had unilateral tumor and all patients had a stage-I disease. Stromal microinvasion was observed in 3 cases. The median follow-up was 60 months (range 7-118 months). One patient had developed a recurrence in contralateral ovary after a unilateral salpingo-oophorectomy. One patient had previous history of urothelial tumor.

Conclusion* Peritoneal staging surgery is not required, because all patients reported had stage-I disease. One recurrence occurred. When reviewing all the 82 cases reported in the literature (included ours), 9\% had previous history or synchronous urothelial tumor suggesting then the need of at least careful checking of urological disease in patients with BBOT.

\section{DEEP LEARNING FOR IMPROVED DETECTION OF PREMALIGNANT LESIONS IN THE FALLOPIAN TUBE, A PROOF OF CONCEPT}

'J Bogaerts*, ${ }^{2} \mathrm{M}$ Van Bommel, 'J Linmans, ${ }^{1} \mathrm{~N}$ Van den Hork, 'J Bulten, ${ }^{2} \mathrm{~J}$ De Hullu, ${ }^{1} \mathrm{M}$ Simons, ${ }^{1} \mathrm{~J}$ Van der Laak. 'Radboud University Medical Center, Pathology, Nijmegen, Netherlands; ${ }^{2}$ Radboud University Medical Center, Gynecologic oncology, Nijmegen, Netherlands

\subsection{6/ijgc-2021-ESG0.533}

Introduction/Background* Risk reducing salpingo-oophorectomy is an effective intervention to reduce the risk of high 